\title{
Representação do bom professor na perspectiva dos alunos de arquivologia
}

\section{Leonina Amanda Feitoza}

\author{
Graduada em Arquivologia pela Universidade \\ Estadual de Londrina (UEL); Docente do \\ Departamento de Ciência da Informação/UEL - \\ Curso de Arquivologia.
}

Julce Mary Cornelsen

\begin{abstract}
Mestre em Ciências da Comunicação; Doutoranda da Universidade do Porto; bolsista da Fundação de Ciência e Tecnologia de Portugal (FCT). Docente do Departamento de Ciência da Informação/Universidade Estadual de Londrina (UEL).
\end{abstract}

Silza Maria Pasello Valente

Doutora em Educação; Docente do Departamento de Educação/UEL

Aponta e identifica as características do Bom Professor na perspectiva dos alunos do Curso de Arquivologia da Universidade Estadual de Londrina, Paraná, Brasil. O instrumento de coleta dos dados foi um questionário, abrangendo uma população de 32 alunos. A análise dos dados utiliza múltiplas dimensões de Candau (1983). Propõe uma Didática partindo da análise da prática pedagógica real. A atuação do professor, ou seja, sua didática necessita compreender o entrelaçamento de três dimensões: a humana, a técnica e a política.

Palavra-chave: Alunos; perspectivas dos bons professores - Curso de Arquivologia - Londrina/Paraná.

\section{The representation of the "good teacher" from the Archivology's students}

This paper points out and identifies the characteristics of a "good teacher" according to the students of the Archivology course from the State University of Londrina, Parana, Brazil. The instrument for data collection was a 
questionnaire encompassing a population of 32 students. Data analysis was based on the multiple dimensions of Candau (human, technical and political) that propose a didactics from the analysis of the real pedagogical practice.

Key-words: Pupils; perspectives of the good professors Course of Arquivologia - Londrina/Paraná.

Recebido em 12.04.2007 Aceito em 20.07.2007

\section{Introdução}

O conceito de educação é determinado por uma série de valores individuais e sociais. Portanto, ao se desenvolver estudos relacionados a este tema, faz-se necessário que se expresse essa correlação e que educador e educando dela sejam bem conscientes, visto que as ações pedagógicas dependem, entre outros elementos, de como o professor e o aluno compreendem o homem, a natureza, a sociedade e o conhecimento.

A educação é considerada por muitos autores, como um processo amplo, que tem por finalidade a realização do homem, em sua plenitude, como expressam Pimentel (1993) e Mizukami (1986), entre outros autores preocupados com esta questão.

$O$ processo educativo se concretiza de maneira informal e formal. Ele ocorre de maneira formal nas instituições criadas especialmente para este fim; e de maneira informal em todas as situações vivenciadas pelos seres humanos, nos mais diferentes espaços e através de diversos meios. Igreja, família, meios de comunicação, situações de lazer, escola, entre outros, consistem em espaços e formas de educação.

Embora o professor não possa ser visto isoladamente dos demais fatores intervenientes no processo educacional escolar, devemos ter em mente, no entanto, que é imprescindível para o desenvolvimento do processo ensino e aprendizagem. Apesar de não ser o único elemento significativo, é ao professor que cabem as tomadas de decisão, constituindo-se, portanto, em peça fundamental, tanto para favorecer a permanência quanto a mudança da cultura institucional, pela sua possibilidade de dar direção à prática pedagógica que desenvolve.

É claro que a importância e o significado do papel do professor não dependem exclusivamente dele, visto ser a escola uma instituição social. Reconhece-se, portanto, que o valor do professor é atribuído pela sociedade na qual atua e na qual se constitui e reconhece.

Compactuando com a perspectiva de que as experiências de vida e o ambiente sócio-cultural são componentes explicativos do desempenho atual do professor, Cunha (1998, p.53) afirma que "o conjunto de valores e crenças que dão escopo à performance dos docentes são frutos de sua história e suas experiências de vida dão contornos ao seu desempenho". 
A forma de ser do professor é um todo e depende, certamente, da cosmovisão que ele possui. Não se sabe até que ponto é importante ou possível classificar as atitudes dos professores. Até porque suas atitudes, como fruto da contradição social, nem sempre apresentam formas lineares e totalmente coerentes com uma corrente filosófica.

Cunha (2001, p. 72) detectou em pesquisa realizada com vistas à consecução de sua tese de doutorado, que, na visão dos alunos, "Bom Professor" é aquele que domina o conteúdo, escolhe formas adequadas de apresentar a matéria e tem bom relacionamento com o grupo". A autora chama a atenção para o fato de que os alunos pesquisados, somente em raras situações, referiram-se ao posicionamento político do professor.

Constatou, ainda, que os docentes apontados como "Bons Professores" continuavam trabalhando, preponderantemente, na perspectiva da reprodução do conhecimento, atitude essa aceita pelos alunos.

Em muitas situações, o professor age de acordo com a expectativa que sobre ele se joga, mas em outras procura construir um novo papel, com contornos ainda pouco claros, mas intensamente desejados.

Rangel (2001), outra autora que se debruçou sobre esse objeto de estudo, diz que, embora, nos depoimentos sobre o "Bom Professor", o domínio da matéria se apresente no conjunto de idéias que expressam as boas condições do ensino, essa presença não se dá numa perspectiva de entendimento da relação forma-conteúdo (entendendo-se o conteúdo como estruturante do método), mas numa perspectiva de relação com habilidades de desempenho do professor. Não se pode, entretanto, esquecer que a influência do conteúdo na escolha da forma de ensinar é um dado importante à compreensão do processo ensino-aprendizagem.

Para Candau (1983), que propõe uma Didática que assuma múltiplas dimensões e que, partindo da análise da prática pedagógica real, forneça os instrumentos para sua transformação, a atuação do professor, ou seja, sua didática, necessita compreender o entrelaçamento de três dimensões: a humana, a técnica e a política.

Para a dimensão humana o centro do processo de ensinoaprendizagem é a relação interpessoal. Essa abordagem leva a uma perspectiva eminentemente subjetiva, individualista e afetiva do processo de ensino-aprendizagem.

A dimensão técnica, sendo objetiva e racional, se refere ao processo de ensino-aprendizagem como ação intencional, sistemática, que procura organizar as condições que melhor propiciem a aprendizagem. Essa dimensão é privilegiada, analisada de forma dissociada de suas raízes político-sociais e ideológicas, e vista como algo "neutro" e meramente instrumental.

Já a dimensão política dá ênfase ao processo de ensinoaprendizagem como um todo. Ela acontece sempre numa cultura específica, trata com pessoas concretas que têm uma posição de classe definida na organização social em que vivem. Essa dimensão não é um aspecto do processo de ensino-aprendizagem. Ela impregna toda a prática 
pedagógica que, querendo ou não (não se trata de uma decisão voluntarista), possui em si uma dimensão político-social.

Segundo Cunha (2001, p. 65):

Não há dúvida que existe entre o aluno e o professor um jogo de expectativas relacionadas aos respectivos desempenhos. "A escola como instituição social determina aos seus próprios integrantes os comportamentos que deles se espera. Por outro lado, como instituição social, ela é determinada pelo conjunto de expectativas que a sociedade faz sobre ela. Este fluxo é que reproduz a ideologia dominante"

Afirma, ainda, a referida autora, que se pode notar a existência de um certo consenso a respeito dos comportamentos que se espera de um aluno e o mesmo acontece com relação ao professor. Isso significa que parte da relação professor-aluno já é predeterminada socialmente. O modelo de sociedade define o modelo de escola e nele está contida a ideologia dominante.

A instituição também interfere na expectativa, tanto dos professores como dos alunos. O ambiente institucional passa essa idéia de ordem aos integrantes da sua comunidade e esses valores passam a ser parte das expectativas dos alunos.

A escolha que o aluno faz do "Bom Professor" é, portanto, permeada por sua prática social, isto é, o resultado da apropriação que ele faz da prática e dos saberes histórico-sociais. Como Cunha (2001, p.67) ressalta, a apropriação é uma ação recíproca entre os sujeitos e os diversos âmbitos ou integrações sociais. Só que elas são diversas nos sujeitos, ou seja, eles fazem apropriações diferentes em função de seus interesses, valores, crenças, experiências etc. Isto é demonstrado pela diferenciação existente entre o comportamento dos alunos quando propõem o "Bom Professor".

A idéia de "Bom Professor" é variável entre os alunos porque contém, em si, a expressão de um valor. O momento da vida das instituições escolares determina, em algum grau, a situação do aluno. Essa situação cria necessidades. Assim, o professor que corresponde a elas tem maior probabilidade de ser considerado o melhor docente.

Visando a caracterizar os "Bons Professores", na perspectiva dos alunos do $4^{\circ}$ ano do curso de Arquivologia da Universidade Estadual de Londrina, optou-se pela pesquisa descritiva-exploratória, de caráter qualitativo, tendo respectivamente como população alvo e instrumento de coleta de dados, o $4^{\circ}$ ano do curso de Arquivologia e um questionário com duas questões abertas.

A opção pela quarta série deveu-se ao entendimento de que, por estarem cursando a última série, os alunos teriam a possibilidade de fazer uma análise abrangente do processo formativo vivenciado no curso de graduação.

O questionário utilizado conteve questões que visavam a traçar a caracterização pessoal dos sujeitos pesquisados. Foram questões abertas, 
principalmente pelo fato que elas justificam respostas e também porque não era intuito da proponente do estudo induzir respostas.

$\mathrm{Na}$ primeira questão foi solicitado aos respondentes que indicassem de três a cinco características que devem possuir os professores que em suas perspectivas são "Bons Professores". Dessa forma essa questão apontaria as características dos "Bons Professores" no plano ideal.

Já na segunda questão foi solicitado que os respondentes indicassem os professores do curso de Arquivologia que consideravam "Bons Professores" por possuírem todas ou algumas das características que foram apontadas na primeira questão. Assim, chegaria-se às características dos "Bons Professores" do curso de Arquivologia no plano real.

\section{Características do bom professor no plano ideal}

Os alunos, ao indicarem as características que devem apresentar os "Bons Professores", no plano ideal, apontaram 100 características, das quais 59 (59\%) pertinentes à Dimensão Técnica e 41 (41\%) à Dimensão Humana. Não foram indicadas características que, ao realizar a análise, a pesquisadora pudesse incluir na categoria Dimensão Política. As Tabelas 1 e 2 evidenciam o exposto:

TABELA 1 - Freqüência e percentual das características do "bom professor" na perspectiva dos alunos: dimensão técnica

\begin{tabular}{|l|c|c|}
\hline Características & Freqüência & $\mathbf{\%}$ \\
\hline Dinamismo & 7 & 11,86 \\
\hline Clareza na exposição dos conteúdos & 4 & 6,77 \\
\hline Didática & 9 & 15,25 \\
\hline Domínio do assunto & 16 & 27,11 \\
\hline Controle da sala de aula & 4 & 6,77 \\
\hline Organização & 8 & 13,55 \\
\hline Experiência & 3 & 5,08 \\
\hline Estilo nas apresentações & 3 & 5,08 \\
\hline Ligação da teoria com a prática & 2 & 3,38 \\
\hline Segurança & 1 & 1,69 \\
\hline Linguagem adequada & 2 & 3,38 \\
\hline Total & 59 & \\
\hline
\end{tabular}

Nota-se na TAB 1 , que mais de $50 \%$ das características apontadas foram de caráter técnico. Dentre as características de dimensão técnica, 0 "domínio de assunto ou conteúdo" foi a que atingiu maior número de indicações (16) equivalente a $27,11 \%$ das características enquadradas na Dimensão Técnica, seguido da "didática", com 9 votos (15,25\%). Logo após, vem "organização", com 8 votos (13,55\%) e "dinamismo" com 7 votos $(11,86 \%)$. Nota-se que "clareza na exposição dos conteúdos" e "controle da sala de aula" receberam o mesmo número de votos: 4 $(6,77 \%)$, seguidos de outro empate entre as características "experiência" e "estilo" nas apresentações com 3 votos cada (5,08\%). Nos últimos lugares estão: "ligação da teoria com a prática" e "linguagem adequada" 
com 2 indicações $(3,38 \%)$ e "segurança" com 1 voto (1,58\%). Pode-se, portanto, constatar que não é só na literatura que se encontram questões atinentes ao processo ensino-aprendizagem, que enfatizam a Dimensão Técnica. Nota-se, nitidamente, nas respostas dadas pelos alunos, a prevalência desta dimensão.

Tabela 2 - Freqüência e percentual das características do "bom professor" a perspectiva dos alunos: dimensão humana

\begin{tabular}{|l|c|c|}
\hline Características & Freqüência & \% \\
\hline Amigo & 3 & 7,31 \\
\hline Empenhado & 3 & 7,31 \\
\hline Empatia / interesse pela disciplina & 5 & 12,19 \\
\hline Aceita opiniões & 2 & 4,87 \\
\hline Compreensivo & 4 & 9,75 \\
\hline Respeitador & 3 & 7,31 \\
\hline Incentivador & 6 & 14,63 \\
\hline Bom relacionamento interpessoal & 2 & 4,87 \\
\hline Participativo & 1 & 2,43 \\
\hline Imparcial & 2 & 4,87 \\
\hline Atencioso & 2 & 4,87 \\
\hline Educado & 1 & 2,43 \\
\hline Espontâneo & 1 & 2,43 \\
\hline Criativo & 1 & 2,43 \\
\hline Amor pela profissão & 2 & 4,87 \\
\hline Sensato & 1 & 2,43 \\
\hline Simplicidade & 1 & 2,43 \\
\hline Paciente & 1 & 2,43 \\
\hline Total & 41 & \\
\hline
\end{tabular}

Na TAB. 2, verifica-se que os alunos, embora tenham apontado um menor número de características no que se refere à Dimensão Humana, ainda assim a valorizaram bastante, pois $41 \%$ das características derivadas das representações que os alunos fazem do "Bom Professor", no plano ideal, são enquadradas nessa categoria. Dentre as características apontadas, nota-se que "ser incentivador" é uma característica apontada pela maioria dos alunos ( 6 indicações, 14,63\%), seguida da característica "empatia / interesse pela disciplina" (5 indicações, 12,19\%) e "compreensivo" com 4 indicações $(9,75 \%)$. Logo após vêm "amigo", "empenhado" e "respeitador" com 3 indicações $(7,31 \%)$ cada uma. "Aceita opiniões", "bom relacionamento interpessoal", "imparcial", "atencioso" e "amor pela profissão" estão empatadas com 2 indicações (4,87\%) cada uma delas. Por último vêm as características: "empatia pela disciplina", "participativo", "educado", "espontâneo", "criativo", "sensato", "simplicidade" e "paciente", com 1 indicação cada (2,43\%).

Esses resultados são similares aos do estudo de Cunha (2001), ou seja, quinze anos após a pesquisa de sua tese de doutorado, defendida em 1988, a representação que os alunos fazem dos bons professores continua privilegiando as dimensões técnica e humana e desconsiderando a dimensão política. 


\section{Características do bom professor no plano real}

Na segunda questão solicitou-se aos alunos que indicassem os "Bons Professores" do curso de Arquivologia apontando as suas características.

Dos 28 professores do Curso de Arquivologia, dezenove $(67,86 \%)$ foram apontados como Bons Professores. Os alunos, ao se referirem aos Bons Professores do seu próprio curso apontaram 157 características, sendo 95 (60,50\%) na Dimensão Técnica e 62 (39,49\%) na Dimensão Humana. Vejamos a seguir as características dos quatro professores que receberam o maior número de indicações por parte dos alunos. Vale esclarecer que algumas das características apontadas, pelos sujeitos, foram agrupadas em razão da semelhança que apresentaram.

Os "Bons Professores" apontados pelos alunos: características de sua atuação:

Professor 2 - apontado como "Bom Professor" por 13 alunos (48,15\%).

\begin{tabular}{|l|l|l|}
\hline \multicolumn{1}{|c|}{ Dimensão Técnica } & \multicolumn{1}{c|}{ Dimensão Humana } & Dimensão Política \\
\hline - Certeza do que & - Empatia pela disciplina & \\
\hline - Qualificação & - Jeito querido & \\
\hline - Domínio do conteúdo & - Dedicado & \\
\hline - Estilo nas apresentações & & \\
\hline - Controle da sala de aula & & \\
\hline - Preparo & & \\
\hline - Didática & & \\
\hline
\end{tabular}

Professor 7 - apontado como "Bom Professor" por 15 alunos (55,55 \%).

\begin{tabular}{|l|l|l|}
\hline \multicolumn{1}{|c|}{ Dimensão Técnica } & \multicolumn{1}{c|}{ Dimensão Humana } & \multicolumn{1}{c|}{ Dimensão Política } \\
\hline - Experiência & - Empatia pela disciplina & \\
\hline - Dinamismo & - Carinhoso & \\
\hline - Domínio do assunto & - Compreensivo & \\
\hline - Didática & - Incentivador & \\
\hline - Boa desenvoltura oral & - Amigo & \\
\hline - Controle da sala de aula & - Dedicado & \\
\hline - Preparo & & \\
\hline - Clareza na exposição dos & & \\
conteúdos & & \\
\hline
\end{tabular}

Professor 3 - apontado como "Bom Professor" por 18 alunos (66,66 \%).

\begin{tabular}{|l|l|l|}
\hline \multicolumn{1}{|c|}{ Dimensão Técnica } & \multicolumn{1}{c|}{ Dimensão Humana } & Dimensão Política \\
\hline - Dinamismo & - Empatia pela disciplina & \\
\hline - Experiência & - Amor pela profissão & \\
\hline - Domínio do assunto & - Amigo & \\
\hline - Incentivador & - Aceita opiniões & \\
\hline - Didática & - Interessado & \\
\hline - Segurança & - Participativo & \\
\hline - Controle da sala de aula & - Simplicidade & \\
\hline - Preparo & - Paciência & \\
\hline - Didática & - Dedicado & \\
\hline - Clareza na exposição dos & - Empenhado & \\
conteúdos & & \\
\hline
\end{tabular}


Professor 5 - apontado como "Bom Professor" por 18 alunos (66,66 \%).

\begin{tabular}{|l|l|l|}
\hline \multicolumn{1}{|c|}{ Dimensão Técnica } & \multicolumn{1}{c|}{ Dimensão Humana } & Dimensão Política \\
\hline - Didática & - Empatia pela disciplina & \\
\hline - Experiente & - Compreensivo & \\
\hline - Domínio do assunto & - Amigo & \\
\hline - Dinamismo & - Participativo & \\
\hline - Clareza na exposição dos conteúdos & - Incentivador & \\
\hline - Estilo na apresentação & - Aceita opiniões & \\
\hline - Preparo & - Dedicado & \\
\hline - Organizado & - Paciência & \\
\hline - Ligação da teoria com a prática & & \\
\hline
\end{tabular}

Com o objetivo de clarear os percentuais dos votos que cada "Bom Professor" recebeu, elaborou-se um gráfico ilustrativo.

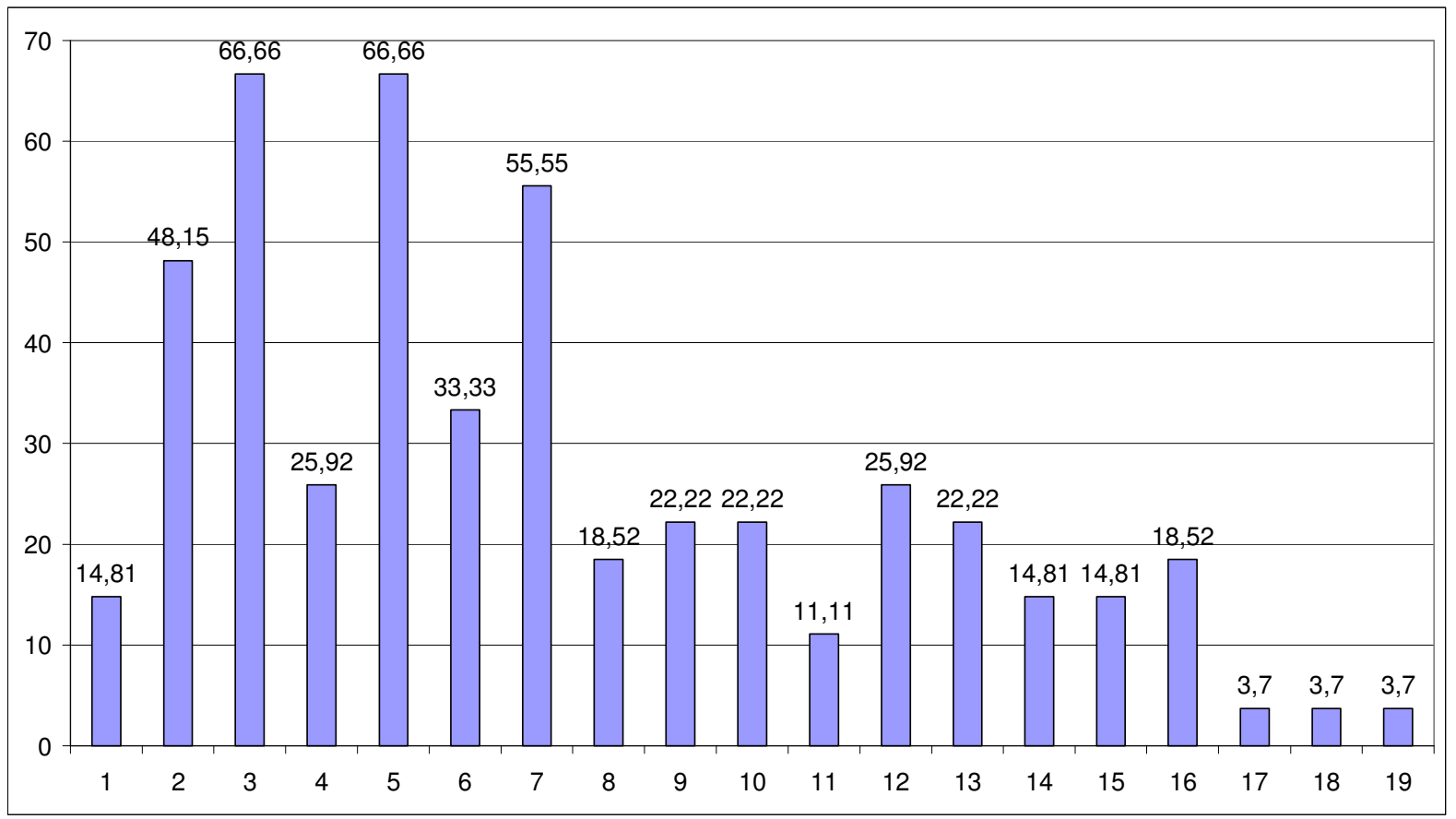

GRÁFICO 1 - Percentual dos votos dos Bons Professores na perspectiva dos alunos

O gráfico demonstra que quatro dos professores foram apontados, pela maioria dos alunos, como Bons Professores: 2, 3, 5 e 7, sendo que os professores 3, 5 e 7 foram apontados por mais de $50 \%$ dos alunos. Um aspecto que chamou a atenção da pesquisadora, ao analisar os dados, foi o percentual de características apontadas pelos alunos ao representarem o Bom Professor no plano ideal, e, posteriormente, no plano real e em relação aos quatro professores considerados como bons, pela maioria dos alunos do curso. O quadro a seguir evidencia os dados: 
Quadro 1 - Percentual dos votos dos Bons Professores no Plano ideal, Real (Curso de Arquivologia e Plano Real (4 melhores do Curso)

\begin{tabular}{|l|l|l|l|}
\hline & $\begin{array}{l}\text { Bom Professor no } \\
\text { Plano Ideal }\end{array}$ & $\begin{array}{l}\text { Bons Professores no } \\
\text { Plano Real (Curso de } \\
\text { Arquivologia) }\end{array}$ & $\begin{array}{l}\text { Bons Professores no } \\
\text { Plano Real (os 4 } \\
\text { melhores do Curso de } \\
\text { Arquivologia) }\end{array}$ \\
\hline $\begin{array}{l}\text { Dimensão } \\
\text { técnica }\end{array}$ & $59,00 \%$ & $60,50 \%$ & $52,45 \%$ \\
\hline $\begin{array}{l}\text { Dimensão } \\
\text { humana }\end{array}$ & $41,00 \%$ & $39,49 \%$ & $47,54 \%$ \\
\hline $\begin{array}{l}\text { Diferença } \\
\text { entre os } \\
\text { percentuais }\end{array}$ & $18,00 \%$ & $21,01 \%$ & $4,91 \%$ \\
\hline
\end{tabular}

Considera-se, a partir dos dados coletados, que, embora a Dimensão Técnica prevaleça nas três formas de abordagem, a diferença entre as dimensões técnica e humana diminui consideravelmente quando os alunos apontam as características dos professores com os quais convivem. A Dimensão Humana, neste último caso, passa a ter um peso bem mais significativo.

\section{Considerações finais}

Os resultados refletem que conhecer os conteúdos, bem como sua área de atuação, é fundamental, quando se deseja ensinar alguém; que possuir habilidades de transferir informações com confiança também é uma competência desejada nos professores. Mas, nem sempre estas características são suficientemente capazes de formar pessoas com um bom nível de conhecimento.

Nota-se que os professores que foram apontados como "Bons Professores" têm características semelhantes e/ou iguais. É visível, portanto, que a dimensão humana é bem valorizada pelos discentes e que ter empatia pelo que faz é fundamental quando se deseja ser um bom professor.

Logo após esta característica, os alunos apontam como "Bom Professor" aquele possuidor do adjetivo incentivador. Parece que os alunos dão, também, muita importância ao professor que consegue envolver os alunos com o processo ensino e aprendizagem.

$\mathrm{Na}$ dimensão técnica, as quatro características mais apontadas, em relação aos Bons Professores do Curso de Arquivologia, foram:

- Domínio do assunto ou conteúdo, por 30,52\% dos alunos; didática, por 17,89\%; dinamismo, por 14,73\% e experiência, por $11,57 \%$.

No que diz respeito à dimensão humana, os alunos de Arquivologia, ao indicarem seus "Bons Professores", apontaram como principais características: dedicação $(20,96 \%)$, empatia pela disciplina $(17,74 \%)$, incentivador $(9,67 \%)$ e amigo $(8,06 \%)$.

Os dados coletados corroboram as conclusões de Cunha (2001) na pesquisa já mencionada neste trabalho, pois, segundo ela, na visão dos alunos então pesquisados, "Bom Professor" é aquele que domina o 
conteúdo, escolhe formas adequadas de apresentar a matéria e tem bom relacionamento com o grupo. Aspectos que ficaram evidenciados, também, na presente pesquisa.

As características apontadas pelos alunos não se enquadram na dimensão política, justamente porque não houve categoricamente respostas condizentes com o conceito de dimensão política presente neste estudo.

Considera-se que essa dimensão é aquela onde se questionam os porquês. O porquê de determinado estudo, o porquê dos resultados desta ou daquela pesquisa ou daquela aula. Questões como essas, acima citadas, merecem especial atenção, quer seja por parte dos docentes, quer seja por parte da instituição de ensino, quer seja pelos alunos. É válido dar importância, também, à dimensão política de ensino. Esta dimensão pode enriquecer as outras duas dimensões, no sentido de alargar os horizontes dos atuais alunos e contribuir para a formação da sua cidadania.

\section{Referências}

CANDAU, V. M. A didática e a formação de educadores: a busca da relevância. Textos, São Paulo, 1983, n. 06, p. 37-41.

CUNHA, M. I. O bom professor e sua prática. 12 ed. Campinas: Papirus, 2001.

CUNHA, M. I. O professor universitário na transição de paradigmas. Araraquara: Papirus, 1998.

MIZUKAMI, M. G. N. Ensino: as abordagens do processo: temas básicos de educação e ensino. São Paulo: EPU, 1986.

PIMENTEL, M. G. O cotidiano do pesquisador na busca da cotidianidade do professor. In: PIMENTEL, M. G. O professor em construção. Campinas: Papirus, 1998, p.23-30.

PIMENTEL, M. G. O professor em construção. Campinas: Papirus, 1993.

RANGEL, Mary. Representações e reflexões sobre o "bom professor". Petrópolis: Vozes, 2001. 